
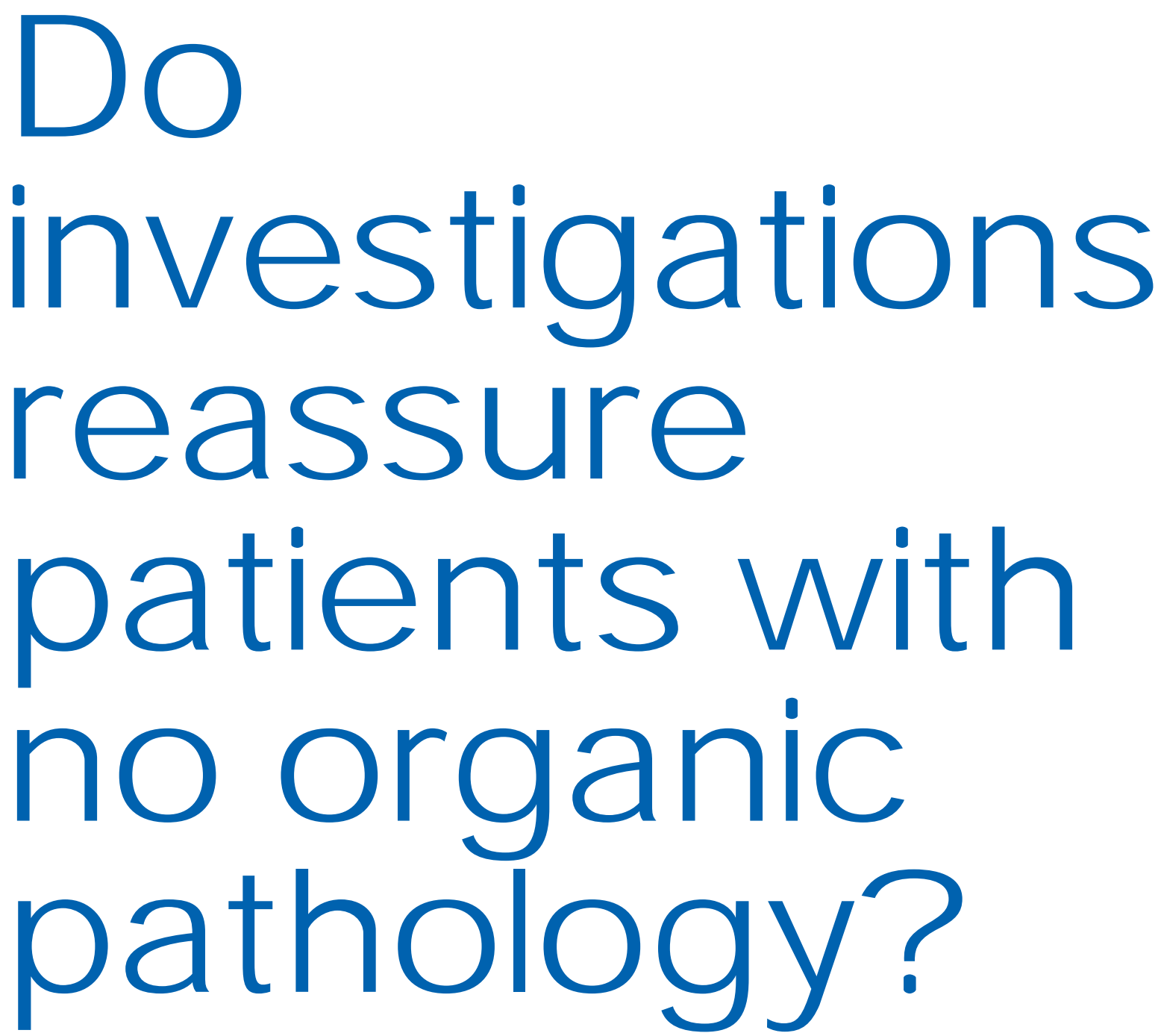

phosphokinaselevels) demonstrated that investigated patients reported lower levels of shortterm disability and increased satisfaction with their consultation compared with patients not investigated, although there was no difference in long-term disability (Sox et al. 1981). However, although demonstrating normal coronary arteries by cardiac catheterization in patients with non-specific chest pain was reassuring in one study (Faxon et al. 1982), other similar studies reported higher levels of functional disability, beliefs that chest disease was present, and psychological distress (Ockene et al. 1980; Potts \& Bass 1993). Also, several observational studies have found that investigations have not predicted symptom resolution or measures of reassurance in patients with benign headache, irritable bowel syndrome or chest pain.

Theseconflicting results may bepartly dueto differences in management in the different clin- ics, as well as differences in the type of patients investigated. Channer et al. found that patients with chest pain associated with neuroses and depression at presentation had not been reassured by a negative exercise test at follow-up, but patients with low levels of anxiety and depression becamepain free(Channer et al. 1987). Likewise, astudy of headachefound that patient satisfaction with the neurological consultation was related to theabsence of anxiety and depression rather than any investigations (Fitzpatrick $\&$ Hopkins 1981). Pre-existing health anxiety does seem to be a factor: in patients undergoing gastroscopy, the news that there was no organic disease gave immediate reassurance, but in thosewith high health anxiety, worries about illness returned to pretest levels within as little as $24 \mathrm{~h}$ (Lucock et al. 1997).

M ostpatientsthereforeappear to bereassured by normal investigations, but patients with high 


\section{Most patients}

\section{appear to be}

\section{reassured by normal}

investigations,

but patients with

high levels of

psychological

morbidity may not

be adequately

reassured levels of psychological morbidity maynotbeadequately reassured. Theoretically they may even bemadeworse, according to cognitivemodels of anxiety. Such models predict that if, after verbal reassurance, the doctor asks for an investigation, the patient may suspect that thedoctor has missed something or is uncertain of the diagnosis, so that subsequently, despite normal results, acycleof further investigationsisinitiated. The neurologist therefore needs to be aware of 'fat folder' patients (i.e patients with a history of numerous consultations and investigations) who havefail led to bereassured about thebenign nature of earlier symptoms and who repeatedly seek reassurance; further investigations in such casesonly reinforcethepatient's belief that even moreinvestigations arenecessary.

Other additional factors will influence the process of reassurance, e.g. the accuracy of patients' medical knowledge and illness beliefs, and cognitive errors such as catastrophizing i.e overestimating the probability of feared events. Doctor variables arealso important. The ability of doctorsto perceivecorrectly their patients' attributions (e.g. cancer as a cause of their symptoms) is related to reduction in patient concerns after theconsultation (Van Dulmen et al. 1995). Doctors' perceptions of pressure from patients to investigate is a stronger independent predictor of doctors' behaviour than patient preferences (Littleet al. 2004); doctors thereforeneed to elicit patients' expectations, and not rely on their own perceptions of pressurefrom patients to investigate, to limit unnecessary use of re sources and iatrogenesis. The communication skills of the doctor, the level of diagnostic uncertainty, and their experience are also likely to determinewhether a patient is reassured by verbal explanation only.

If investigations are requested, the patient is more likely to be reassured if the clinician can use the normal result to modify symptom attribution (Price 2000). For example, in a study of chest pain, outcome was better after angiography in those who accepted that their pain was related to oesophageal disorders than in those who continued to believe in cardiac causes (Ward et al. 1987)

\section{POTENTIAL HARM OF INVESTIGATIONS}

There are potential risks in ordering investigations for the sole purpose of reassurance. For example, ordering investigations influences patients' expectations of future care - patients who were investigated in outpatients weremore likely to feel that investigations should be carried out for symptoms they experienced in the future than patients who were not offered tests (Faxon et al. 1982). Borderline normal or falsepositive findings may lead to unnecessary concerns, further investigations and procedures, any or all of which may bephysically or psychologically harmful (Page \& Wessely 2003). For example, unnecessary anxiety may be created or reinforced, some patients may have an anaphylactic reaction to the intravenous contrast given during neuroimaging, and others may be oversedated if they are claustrophobic during M R scans. Sudlow gives an extreme, though plausible, example of the patient with tension type headache whose M R scan shows an unrelated asymptomatic aneurysm that is coiled endovascularly but the procedure is complicated by a permanent hemiparesis (Sudlow 2002).

\section{HOW TO REASSURE}

The doctor must first establish what the patient thinks is wrong and give the patient the opportunity to fully discuss the problem, and its cause. Studies in patients with headache - and with bowel symptoms - have demonstrated that outpatient consultations can reduce fear of cancer, catastrophizing and actual symptoms by including a discussion of the problem and its cause, whereas investigations did not predict symptom resolution. Blanket reassurance that there is nothing wrong can make the patient feel the doctor is denying the reality of their symptoms. Research has shown that successful reassurance hinges on the patient's perception that the doctor has both understood and acknowledged his or her current problems, and indicated this by using appropriate and acceptableterminology (D onovan \& Blake2000). It is therefore important that the doctor takes a full history and examination, discusses the patient's concerns, and then provides information on the nature of the patient's problem, explicitly addressing any of the patient's underlying fears. Clear information on the presenting problem, explaining the cause of the patients' symptoms, is usually enough to reassurethem.

Of course, some patients are more difficult to reassure than others, particularly those with hypochondriacal personality traits, underlying health anxiety, and high levels of psychological morbidity such as depression or anxiety. Some research suggests that 'wild card effects' can also 
make patients resistant to reassurance, such as seeing a graphic portrayal of death from a particular disease in the media (MCDonald et al. 1996). Fifty-seven percent of patients with worriesabout seriousillnessin astudy of neurological management of headachehad no psychiatric symptomsand their concernsarosefrom acombination of factors- for example, a patient with headache who heard of a neighbour's death from a brain tumour (Fitzpatrick \& Hopkins 1981). In these situations, although an investigation that is not medically indicated may not reassure the patient, it may be cost-effective in their overall management. Otherwise, patients with high levels of anxiety may seek out a second opinion in order to obtain theinvestigation perceived ascrucial in ruling out serious pathology, e.g. a brain scan to check a brain tumour is not causing chronicheadache. Thereis evidence from studies of radiography in back pain that some patients not offered an investigation they perceived to be routine went on to obtain the investigation through another specialist (Jarvik et al. 2003).

It may therefore be helpful to the general practitioner for the specialist to provide a 'final definitive test' so that no further investigations need to becarried out. Although thereis no evidenceto datethat theinvestigation will reassure the patient, our recent randomised trial confirmed that offering abrain scan to patientswith chronic benign headaches and high levels of psychological morbidity significantly reduced subsequent service contacts and costs (H oward et al. in prep.). A 'definitive' test offered in sec-

\section{CONCLUSIONS}

- It is usually both unnecessary and unhelpful to investigate patients who have no organic pathology - patients can usually be effectively reassured by the consultation alone.

- Some patients may be particularly difficult to reassure, and investigations may then be indicated if it is clear to the patient and the general practitioner that this is the final investigation for the symptoms, and that no further referrals or investigations are necessary.

- Investigations in hypochondriacal patients serve to reinforce their need for even more investigations, rather than effectively reassure. ondary care may ther efore help to limit the cycle of unnecessary referrals and further tests, but further research is clearly needed.

\section{ACKNOWLEDGEMENTS}

This paper was reviewed by Dr Jon Stone, Edinburgh

\section{REFERENCES}

Channer KS, James M A, Papouchado M \& Rees R (1987) Failure of a negative exercise test to reassure patients with chest pain. Quarterly Journal of M edicine, 240, 315-22.

Donovan JL \& Blake DR (2000) Qualitativestudy of interpretation of reassurance among patients attending rheumatology clinics: 'just a touch of arthritis doctor?'. British M edical Journal, 320, 541-4.

Faxon DP, M cCabe CH , Kriegel DE \& Ryan TJ (1982) Therapeutic and economic value of a normal coronary angiogram. American Journal of $M$ edicine, $\mathbf{7 3}, 500-5$.

Fitzpatrick R \& Hopkins A (1981) Referrals to neurologists for headaches not due to structural disease. Journal of N eurology, Neurosurgery and Psychiatry, 44, 1061-7.

Hansen JM, Bytzer P, Bondesen S \& Schaffalitzky de Muckadell OB (1991) Efficacy and outcome of an open accessendoscopy service. Danish M edical Bulletin, 382, 88-290.

Howard LM \& Wessely S (1996) Reassurance reappraised - the roleof investigations. Journal of Psychosomatic Research, 41, 307-11.

Jarvik JG, Hollingworth W, Martin B et al. (2003) Rapid magnetic resonanceimaging vs radiographsfor patients with low back pain. JAM A, 289, 2810-8.

LittleP, Dorward M , Stephens K, Senior J \& M oore M (2004) Importance of patient pressure and perceived pressure and perceived medical need for investigations, referral, and prescribing in primary care: nested observational study. British M edical Journal, 328, 44-6.

Lucock M P, M orley S, White C \& Peake M D (1997) Responses of consecutive patients to reassurance after gastroscopy: results of self administered questionnairesurvey. British M edical Journal, 315, 572-5.

M CDonald IG, Daly J, Jelinek VM , Panetta F \& Gutman JM (1996) Opening Pandora's box: theunpredictability of reassurance by a normal test result. British M edical Journal, 313, 329-32.

Ockene IS, Shay M J, Alpert JS, Weiner BH \& Dalen JE (1980) Unexplained chest pain in patients with normal coronary arteriograms. A follow-up study of functional status. New England Journal of M edicine, 303, 124952.

Page L \& Wessely S (2003) Medically unexplained symptoms: exacerbating factors in the doctor-patient encounter. Journal of the Royal Society of M edicine, 96, 223-7.

Potts SG \& Bass CM (1993) Psychosocial outcome and use of medical re sources in patients with chest pain and normal or near-normal coronary arteries. A long term follow-up study. Quarterly Journal of M edicine, 86, 583-93.

Price JR (2000) Managing physical symptoms: The clinical assessment as treatment. J ournal of Psychosomatic Research, 48, 1-10.

Sox HC Jr, M argulies I \& Sox CH (1981) Psychologically mediated effects of diagnostic tests. Annals of I nternational M edicine, 95, 680-5.

Sudlow C (2002) US Guidelines on Neuroimaging in Patients with NonAcute H eadache: a Commentary. Journal of Neurology, N eurosurgery and Psychiatry, $\mathbf{2}$, ii 16-ii18.

Van Dulmen AM , FennisJFM , M okkink H GA, Van Der Velden HGM \& Bleijenberg G (1995) D octor-dependent changes in complaint-related cognitions and anxiety during medical consultations in functional abdominal complaints. Psychological M edicine, 25, 1011-8.

Ward BW, Wu WC, Richter JE, Hackshaw BT \& Castell D O (1987) Long-term follow-up of symptomatic status of patients with non-cardiac chest pain: is diagnosis of eso phageal etiology hel pful? American Journal of Gastroenterology, 82, 215-8. 